[Annesley, B. (1997). Performance Indicators for New Zealand Schools: The Problems and the Potential. New Zealand Annual Review of Education, $6,105-126]$

\section{Performance Indicators for New Zealand Schools: The Problems and the Potential}

\section{BARBARA ANNESLEY}

\section{Abstract:}

In recent years, there have been increasing demands, particularly from governments, for better information about the performance of schools. Performance indicators have been identified and adopted in many countries as a potential solution to the challenge of providing information which demonstrates the efficiency and effectiveness of schools and other education institutions. This article examines the notion of performance indicators, discusses their benefits and limitations, and identifies the characteristics of effective indicator systems. It describes and critically appraises the information and measurement systems that are currently used to assess the performance of New Zealand schools. Finally it considers whether indicators could be utilised more effectively not only to measure, but also to improve the performance of New Zealand schools.

$\mathrm{T}$

he two words "performance" and "indicator" are commonly used and understood, but when used together, represent a concept which is more complex than the sum of its parts. This complexity arises, in part, from the fact that there is a lack of consensus over a precise definition of the term and its application to education organisations or systems (Nuttall, 1994). Even the term "performance indicator" - though the most commonly used - isn't universally accepted. Other terms include: education indicators; effectiveness indicators; quality indicators; productivity indicators; and success indicators (Ruby \& Wyatt, 1988; Wyatt, 1990).

It is important that these definitional differences are recognised, for not everyone who discusses performance indicators is talking about the same thing. One significant area of dissension relates to whether

\section{Barbara Annesley}

performance indicators simply present descriptive information about particular aspects of the education system, or whether they involve some kind of evaluative judgement about how well the education system or institution has performed. There is a key distinction in these two perspectives. While the first merely describes what has happened, the latter involves judging performance against a pre-defined reference point - a standard, target, past performance, or comparison with other schools (Climaco, 1992).

There is a range of viewpoints on whether performance indicators relate only to the outcomes of education, or whether they can be applied to other aspects of the education system, such as inputs, context, processes and outputs. ${ }^{1}$ This relates to understandings of the notion of "performance", and whether it is judged to be a process or an outcome. Ruby and Wyatt (1988), for example, describe performance indicators as:

a particular form of information which assesses the functioning of a system in terms of outcomes. (p. 1, italics added)

In contrast, Climaco (1992) contends that:

The concept of performance leads us further than the notion of results .... Performance deals with the "visibilities" and "invisibilities" of action, and as such it may be expressed by the results of action as well as by the conditions and contingencies under which the action takes place. (p. 297)

A further point on which opinion is divided is whether performance indicators can provide reliable qualitative information. Many commentators, such as Spee and Bormans (1992), consider that indicators must be quantitative. Indeed, the most commonly used performance indicators are numerical expressions such as ratios and percentages. Others (Frater, undated, Chartered Institute of Public and Financial Accountancy, 1988) have argued for the use of qualitative judgements and indicators, noting that they can provide more reliable measures of some dimensions of education.

Although these are significant areas of disagreement, there are also a number of key points relating to performance indicators about which there is consensus. One is that they should enable comparisons of the performance of a unit of measurement (e.g., country or institution) at different times, or with another similar unit (Cuttance, 1989). There is also general agreement that indicators may be applied at any 
organisational level in the delivery of education - national, state, district or region, school or classroom level.

\section{The Uses of Performance Indicators}

The way in which performance indicators are used is closely linked to the way in which they are defined (Wyatt, 1990). Wyatt et al. (1989) identify the primary purpose of indicators as providing educators and other education stakeholders with evidence that schools (or other educational institutions) are doing what they are intended to do. Within this broad purpose is a wide range of potential applications of performance indicator information. Oakes (1986) lists these as:

- informing management decisions;

- explaining the causes of conditions and changes;

- informing policy-makers of the practices that are most effective for improving education;

- monitoring standards and trends;

- forecasting future changes;

- stimulating and focusing effort;

- defining educational objectives;

- ensuring accountability; and

- assessing the impact of education reforms.

The uses to which a particular set of performance indicators are applied will depend on the nature and extent of the information they provide, who "owns" and has access to that information, and the resources available to them. It is unlikely, however, that any single performance indicator system will be able to provide information that can be used for all the purposes listed above. It is more likely that performance indicators will be one of a number of information sources used for each.

\section{Measuring and Evaluating the Performance of New Zealand Schools: Current Practices}

\section{The Framework for Measuring School Performance in New Zealand}

Three key processes form the current framework for monitoring and reporting on the performance of New Zealand schools. These are:

- school self-review;

- external school review; and

- external reporting by schools.
Self-review

Current legislation requires each school in New Zealand to have a "charter". This document provides the basis for the relationship between the Crown and a school's board of trustees. All school charters are"deemed to contain the aim of achieving, meeting and following the National Education Guidelines (Section 61(2) of the Education Act 1989), which are a set of centrally prescribed aims and objectives for education. The National Education Guidelines require boards of trustees to maintain an ongoing programme of self-review. The Education Review Office (ERO) describes self-review as a process by which a board of trustees "identifies, assesses and evaluates the effectiveness of the school in meeting the values it has adopted, fulfilling its obligations to the community and providing the education it wants for its students (ERO, 1994, p. 5). Self-review is not intended to be an end in itself, but to inform board decision-making and be part of a wider process of school improvement.

External Review by the Education Review Office

The Education Review Office was established as part of the Tomorrow's Schools reforms in 1989 to review the performance of schools and other education organisations. ${ }^{2}$ Presently, ERO carries out two main types of school review - assurance audits and effectiveness reviews. Assurance audits evaluate the extent to which schools are behaving lawfully and are meeting the requirements of the legislation, regulations and their charter. Effectiveness reviews "evaluate the contribution made by individual schools to student achievement, in terms of both standards and progress, by the quality of teaching services and management systems and practices" (Ministry of Education, 1995, p. 8). In other words, effectiveness reviews aim to identify and evaluate the way in which schooling processes contribute to the learning outcomes of students.

ERO does not use standardised indicators or criteria of effectiveness to inform its evaluations of school performance. Instead it has developed a set of "standard procedures" which are used by its officers in carrying out assurance audits and effectiveness reviews. Review Officers form judgements about the performance of schools on the basis of these procedures, and their professional knowledge. 
External Reporting

School boards of trustees, as Crown entities, must meet the requirement under the Public Finance Act 1989, to prepare audited annual financial statements, including a statement of objectives specifying what the school will achieve over the ensuing year, and a statement of service performance (SSP), which reports on actual performance against the specified objectives. Under a provision in the Public Finance Act, however, the Minister of Finance has granted boards an exemption from preparing an SSP in each year since 1993.

In addition, Boards of Trustees are required under the Education Act 1989 to table an annual report at an annual general meeting and provide a copy of the report to the Secretary of Education. While the Act does not specify what an annual report should include, it usually contains the school's financial statements and a report from the principal about the activities and achievements of the school and its students.

The Minister of Education is required under the Education Act to present an annual report (known as the school sector report) to Parliament on the performance of the New Zealand school sector as a whole. The report usually includes statistical, financial and evaluative information and is intended to provide a picture of the context, inputs, processes and results (outputs and outcomes) of schooling (Minister of Education, 1996). The Education Act also provides for the Secretary of Education to require boards and management of state and private schools to provide statistical information.

\section{Current Indicators of the Performance of New Zealand Schools}

School management, Government and the wider public use a range of indicators to make judgements about the performance of schools. This information informs self-review and external reporting by individual schools, external review by ERO, and reporting to Parliament by the Minister of Education. The indicators used, and issues associated with them, are discussed below.

School-Based Performance Indicators

One of the key information sources that schools are likely to use in evaluating their performance is student achievement data. Many New Zealand primary schools use nationally normed, standardised tests such as the Progressive Achievement Tests and the Test of Scholastic Abilities (Ministry of Education, 1994). ${ }^{3}$ Most secondary schools collect information on immediate outcome measures, such as success in external examinations, and numbers of students going on to tertiary education and employment. Other information, such as truancy and attendance rates, is also collected in most primary and secondary schools. Boards of trustees possess information about their human and monetary resources and the way in which these are employed and this information may be used for monitoring and reporting purposes.

The extent to which boards and principals use student achievement data and other information to review and report on the performance of the school in meeting its objectives depends on a range of factors, including the nature and level of detail of the data gathered and the extent to which they are aggregated and analysed. The Education Review Office (1994) has observed that schools make insufficient use of student achievement information in evaluating the effectiveness of their practices. This view is further supported by Wylie (1994) who found that aggregated achievement results were reported to the board of trustees in only 24 percent of the schools surveyed.

There has, however, been no specific research or monitoring to determine the extent to which schools utilise indicator systems, or the nature and reliability of such systems. While the absence of empirical information makes it difficult to comment on current practices in this regard, the findings of Wylie (1994) and the Education Review Office (1994) suggest that many New Zealand schools are at a relatively early stage in the development of information systems to enable them to effectively monitor, review and report on their performance.

System-Wide Performance Indicators

The Ministry of Education collects information from schools about staff and students through regular statistical returns. It also carries out and contracts research studies for the purposes of monitoring education trends and policies.

While not all statistics are indicators, much of the statistical data collected from schools is used by the Ministry of Education to construct indicators which provide information about the education system as a whole. Many of these indicators, as well as the evaluative findings of the Education Review Office, are brought together in the Minister of Education's annual statutory report to Parliament.

To date, annual school sector reports have provided some comparative information about inputs and student outcomes over time, but have not drawn comparisons between individual schools. The most 
recent report notes, however, that school principals and boards of trustees will be able to "appraise such indicators for their school both in relation to other schools in their area and nationwide (Minister of Education, 1996, p. 5). The information provided in school sector reports is descriptive rather than evaluative. The indicators used are not referenced against objectives, targets or benchmarks and the report includes very few statements or judgements about the "goodness", "badness" or "quality" of the performance of the New Zealand school system, and none at all about the performance of individual schools. While the indicators contained in school sector reports give a picture of the inputs and outputs of schooling (and to a limited extent, the context), these reports by the Ministry's own admission provide only a limited picture of the processes by which New Zealand schools transform inputs into outputs and outcomes.

The uneven focus of the indicators used in the school sector report calls into question whether the information it draws together constitutes an indicator "system". Current indicators of school performance in New Zealand, as reported in the school sector report, appear to be somewhat ad hoc and unsystematised.

The National Education Monitoring Project

Amongst the recent developments which have resulted from the New Zealand Government's concern to receive better information about the performance of New Zealand school students, individual schools, and the school system as a whole, is the National Education Monitoring Project (NEMP). NEMP is intended to provide a picture of the knowledge, skills, attitudes and values of randomly selected samples of New Zealand students, at years 4 and 8 of the school system (equivalent to Standard 2 and Form 2). The first testing took place in 1995 and focused on the achievements of students in three main areas - Science, Art and Information Skills. The results of these tests have recently been published.

It is intended that the NEMP will cover the full range of curriculum areas over a four year cycle. It addresses a previous gap in the availability of standardised national achievement information for primary schools, and is likely to assist in providing a more accurate picture of learning outcomes for New Zealand students.
Transition Point Assessment

Policy is currently being developed in relation to the implementation of a national system of Transition Point Assessment (TPA). This involves nationally standardised assessment of students at key transition points in their schooling - the beginning of Year 7 (Form 1) and the beginning of Year 9 (Form 3). There is little publicly available documentation about the nature of the proposed TPA system, or its intended uses. Indications are that its principal purpose will be to provide individual schools with comparative information about the achievement of their students.

International Education Indicators

There has been growing international interest in the development of reliable educational indicators for assessing and comparing the performance of national education systems. One of the responses to this has been the establishment of an International Educational Indicators Project (INES) by OECD member countries (Irving, 1993). New Zealand, as one such country, has been involved in the INES project since it was initiated in 1988. In 1992 the first set of internationally comparable indicators relating to the context, inputs, processes and outcomes of schooling were published by the OECD. Most of the indicator information for New Zealand is drawn from existing data sources.

New Zealand has also participated in international studies of student achievement under the auspices of the International Association for the Evaluation of Educational Achievement (IEA). These studies use standardised tests to measure the achievements of a sample of students in specific areas of learning, and provide internationally comparable information about student achievement in different subjects for participating countries. Since joining the IEA in 1968, New Zealand has participated in six studies, the most recent being the Third International Mathematics and Science Study (TIMSS) in 1994/95.

\section{Weaknesses in the Current Framework for Performance Measurement}

The above description signals a number of issues associated with current arrangements for measuring and evaluating school performance. These can be summarised as:

- there is no planned, explicit system of performance indicators for New Zealand schools, at either the national or institutional level;

- current national education indicators are descriptive rather than evaluative; 
- there is no requirement or encouragement for individual schools to develop and use performance indicators;

- many New Zealand schools have yet to develop systems for reviewing their own performance, or for using indicator information for review, management or planning purposes;

- there are few national performance indicators which focus on school processes; and

- current developments in performance measurement are focused on students' achievement outcomes, at the expense of other areas.

Current performance measurement systems in New Zealand are used primarily for accountability and monitoring purposes. This reflects the emphasis of recent policy trends both in New Zealand and internationally. The potential for performance measurement systems to contribute to school improvement has yet to be explored by New Zealand policy makers. This view is supported by a number of New Zealand authors, such as Codd, who argues that current approaches to the evaluation of school performance are "essentially technocratic, producing more effective political control rather than qualitative improvements in teaching and learning" (1989, p. 3).

These issues raise questions about how much we in New Zealand know about how well individual schools and the education system as a whole are performing, and on what basis we make such judgements. They also suggest the need to develop effective indicator systems which enable the achievement of multiple objectives, including monitoring, accountability and school improvement.

\section{Issues in the Use of Performance Indicators in Education}

In assessing the contribution that performance indicators can make to the improvement of schooling in New Zealand it is important to consider the conceptual, epistemological and cultural base which sits beneath them, along with issues related to their reliability and validity, fairness and credibility, value and justification (Hopkins, 1991, p. 4). These issues and underpinnings are discussed below.

\section{The Model of Education Which Informs the Indicator System}

All performance indicators systems are informed by a view or model either implicit or explicit - of how the education system works. This model is a key influence on the indicators selected and therefore, on the type of information that they provide. As Oakes (1986) notes, however, no single model of the educational process has gained universal or even widespread acceptance. Rather, there is a range of views about the important aims and aspects of education. This means that the model or framework which underpins an indicator system is unlikely to be objective or neutral, but will almost always have a bias towards one particular perspective of the education system. Authors such as Nuttall (1994) emphasise the need for the model underlying an indicator system to be acknowledged and made explicit.

\section{The Use of Output and Outcome Measures}

Performance indicators have their origins in economics and management theory, and consequently many performance indicator systems are based on a simple production model of education, focusing on the input-process-output factors in the delivery of educational services.

It is generally accepted that accountability for outputs and outcomes must be consistent with controls over inputs and processes. The outcomes of schooling are, however, strongly influenced by contextual factors which are outside the control of institutions and there is almost complete agreement that they cannot be held solely responsible for student outcomes.

Some authors have questioned the assumption that the outputs and outcomes of education are in fact measurable, regardless of who defines them or is responsible for them. Watt (1990) notes that the education process itself is complex, interactive and long term in its nature, and that many of the significant outcomes of education are difficult to relate directly to specific inputs.

These issues point to the need for performance measures to reflect the "value-added" by schools, and for indicator systems to be based on a model which recognises the complexity of education, including the significance of, and the interactions between, context, inputs, processes and outputs (Ruby, 1994).

\section{The Subjective Nature of Judgements about the "Quality" of Education}

As noted previously, many authors maintain that a defining characteristic of performance indicators is their evaluative function. ${ }^{4}$ An underlying assumption in this function is that "standards", "quality" and "performance" are objective and measurable (Gray \& Wilcox, 1993). 
In reality however, the meaning of these terms is value-laden and subjective. The determination of quality depends, ultimately, on the standards or criteria that are applied. This subjectivity has caused a number of authors to suggest that the objectives or standards against which judgements about performance are made should be explicitly stated.

\section{The Political Nature of Performance Indicators}

Because indicator systems are not merely neutral collections of information, choices about them and their uses are political as well as technical issues (Ruby \& Wyatt, 1988). The selection of particular indicators provides signals about those aspects of schooling which are valued most and those working in schools may focus their efforts accordingly. Taylor Fitz-Gibbon (1996) notes that this may be the intended effect. If so, it is imperative that the factors selected reflect those aspects of school processes which research shows to be linked to school effectiveness and improvement.

\section{System-Wide and School-Based Indicator Systems}

Oakes (1986) distinguishes between "top-down" indicator systems, which are largely determined at a national level and applied across all schools, and "bottom-up" systems consisting of locally developed or school-based indicators. These two types of system provide different information for different audiences and purposes.

Top-down systems usually provide data which can be aggregated to enable generalisations about the education system as a whole. These data can be used for a range of purposes, including policy development, accountability, monitoring, and the allocation of resources.

The primary aim of school-based indicator systems is school improvement through self-evaluation (Wyatt, 1990). As such they tend to provide information which reflects the particular priorities and concerns of individual institutions. This means that very often, the data they provide cannot be aggregated at a national level.

Top-down indicator systems have been criticised on a number of fronts. In particular, they have been accused of providing partial and distorted evaluations, because the summary information they provide conceals extremes, and fails to take into account the different circumstances of subgroups within the population being measured. The aggregated information provided by system-wide performance indicator systems has also been criticised as being of limited use to those workingin schools because it reflects national rather than local interests.

\section{The Use of Performance Indicators for Comparative Purposes}

In some countries, system-wide performance indicators are used to compare the performance of schools. The literature identifies a number of problems associated with this usage.

First, comparability requires the use of identical or parallel methods for the collection of information, something which is difficult to achieve across multiple collection sites. The wide-ranging factors which affect the comparability of information are often neglected in the aggregation of data. Examples of this include definitional issues such as exactly who is counted as a teacher when teacher-pupil ratios are being measured, and what counts as truancy when rates of attendance are being compared.

Flynn (1986) maintains that comparisons should not be made between schools, but only over time for the same organisation. Comparisons of this nature provide relevant information for management purposes and enable schools to monitor their progress against benchmarks established by past performance.

\section{Resistance to Performance Indicators}

A significant issue in the success of performance indicator systems is the extent to which they are accepted by various stakeholders. This acceptance is likely to depend on who develops the system, who chooses the indicators, and what their purpose is to be.

Helsby and Saunders (1993) note that many teachers regard the use of performance indicators as a move to deprofessionalise educators. There is a perceived tension between the use of indicators for external accountability and the demands of educators for professional autonomy (Cuttance, 1989).

A number of authors maintain that performance indicators are likely to encounter less resistance if they form part of a strategy for improving the managerial capacity of institutions and have no selective function or role in resource allocation or quality control (Spee \& Bormans, 1992). In addition, those working in a school are more likely to change their practices if the information collected is relevant at a local level and is "owned" by the school itself (Gray \& Wilcox, 1993). 


\section{The Cost of Performance Indicator Systems}

The development and implementation of performance indicator systems involves significant costs in terms of time, money, expertise and opportunity costs. Each individual dimension or factor that is measured and each separate data source used adds to the cost of the system. Using data intended for other purposes is one way of minimising costs, but this can often involve the use of inappropriate or proxy measures, resulting in inaccurate information.

Cuttance (1994) notes an inherent tension in the need to provide a comprehensive picture of the activities and outcomes achieved at a particular level of the education system and the generally accepted view that the number of indicators should be kept small, in order to assist their comprehensibility and accessibility. An indicator set which is small may be more manageable but it may also be less valid and fail to represent all the key aspects of the education system or institution.

\section{The Characteristics of Effective Indicator Systems}

Although a range of significant issues are identified above, they should not be taken to mean that the use of indicators in education is entirely problematic and that indicator systems are unable to be implemented in an effective way. Rather, these difficulties should be appreciated and indicator systems developed which overcome or diminish them.

Some of the principles and characteristics which are important to the development of effective indicator systems are identified in the preceding discussion. These can be summarised as:

- the need for the model which informs the indicator system to be explicit, and the requirement for it to recognise the range and complexity of factors which contribute to education outcomes;

- the need to be explicit about the objectives and criteria used as a basis for evaluating performance;

- the need to develop indicators which are valid and reliable and which do not have a corrupting effect on individual or organisational behaviour;

- the need for indicator systems to include a range of qualitative and quantitative measures;

- the need for indicators to be used in conjunction with other forms of monitoring and evaluation;

- the need to develop complementary systems of both school-based and national indicator systems;
- the need for caution in using indicators for comparative purposes;

- the desirability of indicator systems which focus on schooling improvement as well as accountability;

- the need to balance the cost and manageability of indicator systems against the provision of a comprehensive and accurate picture of the organisation or system.

\section{Future Directions for Performance Indicators in New Zealand Education}

Taking into account the principles and characteristics identified above, it is possible to identify three ways in which performance indicators can be used more effectively to measure and improve the performance of New Zealand schools. These are:

- through the development of school-based performance indicators;

- through the development of process indicators; and

- through the development of systems for feeding-back central indicator information to individual schools.

\section{School-Based Performance Indicators}

There are a number of imperatives for the development of school-based indicators in New Zealand. The importance of performance indicators for effective local management of schools was recognised six years ago by a Ministerial Working Party on Assessment for Better Learning (1990), which recommended to the New Zealand Government that the Ministry of Education should supply the boards of trustees and staff of schools with information about the nature and use of performance indicators. No action has yet been taken with respect to the implementation of this recommendation.

A second consideration is the requirement under the National Education Guidelines for school boards to follow sound management practices. Brown (1992) asserts that in education such practices involve:

- the establishment of clear management responsibilities;

- the determination of clear goals, objectives and standards;

- strategic planning.

- $\quad$ strategies for effective resource management; and

- the use of performance indicators to measure progress towards goals. 
A further consideration is the requirement for boards to prepare annual statements of service performance (SSPs) in which they report progress towards the objectives specified at the beginning of the year. Indications are that the exemption which has applied to this requirement for the last five years will not be continued in the future. In order to prepare SSPs, schools will need to develop or have access to indicators through which they can measure and report their success in meeting their objectives.

Options for the Introduction of School-Based Indicators in New Zealand

There are two feasible options for the introduction of school-based indicator systems in New Zealand, within the current monitoring and accountability framework.

The first is for the Education Review Office to devise and use performance indicators in its reviews of individual schools. The use of common indicators across all schools would provide ERO with an objective framework for judgements about the quality of individual New Zealand schools and the system as a whole. The provision of information to schools about the indicators used by ERO would enable them to not only prepare for the review but also to reflect on the quality of their practices. Schools themselves could utilise the indicators developed by ERO, with the validity of information subjected to scrutiny as part of the external review process.

There are, however, several difficulties with this approach. One is that indicators used primarily for external review purposes may be regarded by those in schools as mechanisms for accountability and control rather than school improvement. A second issue is that the application of externally derived process indicators may lead schools to adopt uniform practices which reflect the factors which are measured, thus stifling innovation and responsiveness to local needs. In addition, such an approach is likely to be rejected by ERO as inconsistent with its view that its role is not "to impose its own interpretations of specifications or standards" (Laugeson, 1993, p. 10).

The second option is for the Ministry of Education to develop a set of optional performance indicators, from which schools could select those which are most appropriate to their situation. These indicators could be used for self-review, for reporting to government and the local community, and to provide information to the Education Review Office for external review purposes. This approach might also involve the Education Review Office in evaluating the performance indicator systems adopted by schools, and subjecting their findings to external scrutiny. Such an approach has been adopted in France, where schools have been provided with a wide range of indicators to assist them to review their own performance (OECD, 1996).

\section{School Process Indicators}

Many of the indicators currently used to monitor and evaluate the performance of New Zealand schools (both individually and collectively) relate to student achievement, as measured in standardised tests, external examinations and more recently (in the National Education Monitoring Project), against the achievement objectives set down in curriculum statements.

The outcomes of education are complex and wide ranging and it is widely acknowledged that examination and test results on their own are not sufficient measures of the performance of schools. It is problematic, therefore, to seek to measure or describe the quality of education solely in terms of student achievement. For this reason, there is increasing interest in the use of "process indicators" as part of wider performance indicators systems (Scheerens, 1990; Taylor Fitz-Gibbon, 1994).

The focus of process indicators in education is on what actually happens in schools. An assumption underpinning their use is that the ways in which human and other resources are organised and deployed in schools relates to or affects outcomes (Gray \& Wilcox, 1995). Such an assumption is grounded in school effectiveness research which has established that particular characteristics and practices within schools are positively correlated with student achievement and other desirable outcomes, such as low levels of truancy and positive student attitudes to learning. Indeed, a number of authors have developed process indicators which are derived from school effectiveness and school improvement research (e.g., Hopkins, 1991).

The introduction of appropriate school process indicators in New Zealand schools is likely to support effective self-review and to provide both national and local decision-makers with information about the extent to which schools have in place practices and processes which support positive student outcomes. Process indicators are also likely to provide additional information to support external evaluations of school effectiveness by the Education Review Office. 


\section{"Feed-Back" Systems for National Indicators}

Because national and school-level indicator systems usually have different objectives, applications and audiences, it is important to have indicators at both these levels.

In addition to the development of school-based performance indicator systems, there are strong arguments for "feeding-back" indicator information collected at a national level to individual schools (Taylor Fitz-Gibbon, 1996). Such a step ensures that both Government and school decision-makers benefit from system-wide indicators, and is particularly important in systems where a significant proportion of decision-making takes place at the school level, as occurs in New Zealand.

In some countries, such as the United Kingdom, authorities have fed-back outcome-related indicator information to schools through public comparisons or "league tables". There are difficulties associated with such an approach. Simple comparisons between schools on the basis of outcome information are misleading because they ignore the non-school factors which contribute to student achievement. In addition, schools may resist providing information or manipulate data in order to enhance their performance (e.g., by limiting student entry to examinations to those who are likely to pass).

A less problematic approach is for schools to be provided with information about their own school, along with aggregated information relating to the system as a whole, schools with similar socio-economic and/or demographic characteristics and possibly, information about "expected" student achievement results, taking into account student intake variables. Such an approach would enable schools to utilise the information in whatever way they wished - be it for self-review, development planning or external reporting purposes.

In New Zealand, there is clearly a need to complete the "feedback loop" to schools in relation to indicator information drawn from routinely collected data. Advances in computer technology make the feeding-back of a wide range of data to individual schools an increasingly realistic objective, and one which should be explored further in New Zealand by the Ministry of Education.

The Transition Point Assessment programme which is currently under development is likely to provide primary and intermediate schools with feedback about how the achievements of their students compare with those of students nationally, and in schools with similar student intakes. A critical factor in the usefulness of this information for school improvement purposes, however, will be the extent to which teachers, principals and trustees are educated in using it appropriately and effectively.

\section{Conclusion}

Performance indicators identify the principal features or elements of successful performance. They can be expressed as either quantitative measures or as qualitative statements. They are intended to provide a "snapshot" of a school's performance at a particular point in time.

Performance indicators are more than simple statistics, however. As demonstrated in the preceding discussion, they are complex and controversial and there are a number of pitfalls associated with their development and implementation. These factors have led a number of authors to establish principles and identify characteristics associated with effective performance indicator systems. A number of these principles and characteristics have been identified in this article. They are outlined more fully by Cuttance (1994), Nuttall (1994), Oakes (1986), Riley (1994), Taylor Fitz-Gibbon (1996) and Wyatt et al. (1989).

While performance indicator systems have been part of the response in many countries to the demand for more and better information about school performance, this is not the case here. New Zealand has no planned, explicit performance indicator system at the national level, and currently the development of such systems at the institutional level is neither required nor actively encouraged.

New Zealand's present system for monitoring and evaluating the performance of individual schools and the sector as a whole is problematic in a number of other ways. National education indicators are descriptive rather than evaluative, focus primarily on the outcomes rather than the processes of schooling and are intended primarily for accountability purposes rather than as tools for schooling improvement. As such they fail to adequately represent the range and complexity of variables which impact on education outcomes.

This article proposes that there are three key ways in which these deficiencies can be addressed:

- through the adoption of strategies to encourage the use of performance indicators in schools;

- through the development of process indicators, drawing on the findings of research on school effectiveness and school improvement; and 
- by feeding back centrally collected indicator information to individual schools.

A well-designed system of performance indicators which encompasses these facets has the potential to make a valuable contribution to the assessment and improvement of the quality of schooling in New Zealand. Such a system should be informed by the principles and positive characteristics which are identified in the preceding discussion.

It is time for the New Zealand Government to give careful consideration to the potential of performance indicators - not as instruments of accountability or control - but as mechanisms for enabling schools to manage effectively and constantly improve the education they provide to their students.

\section{Notes}

1. Contextual factors are those features of the situation which are outside the control of the school but which affect outcomes (Taylor Fitz-Gibbon, 1996). The resources or inputs of education are the buildings, salaries, equipment and other factors used to produce education services. The education process consists of all the factors which are part of the delivery of education services. These processes include the governance and management of education, the methods used in the provision of teaching and support services to students. Outputs in education include the instructional and other services of various kinds to which students are exposed. The outcomes of education are twofold: the immediate effects for individuals in terms of enhanced knowledge, skills and attitudinal change; and the long term effects on society which occur as a result of the attainments and experiences of individuals in the school system (Ministry of Education, 1990).

2. See Laugeson (1993) for a full discussion of the history of the establishment of the Education Review Office, and the changes which have occurred in its defined role and functions since 1989.

3. These standardised tests, with national age- and class-norms for primary and lower secondary school students, were prepared by staff of the New Zealand Council for Educational Research for use by classroom teachers for instructional purposes. However, they were not specifically designed, or recommended, for use in providing performance indicators for schools, or for national monitoring.
4. Evaluation is the process of obtaining and using information to make interpretations or judgements (Codd, 1989).

\section{References}

Brown, S. (1992). Raising standards: Factors influencing the effectiveness of innovations. In Critical reflections on curriculum policy. Edinburgh: Scottish Council for Research in Education.

Chartered Institute of Public Finance and Accountancy. (1988). Performance indicators in schools: A contribution to the debate. London: CIPFA.

Climaco, C. (1992). Getting to know schools using performance indicators: Criteria, indicators and processes. Educational Review, 44 (3), 295-308.

Codd, J. (1989). Evaluating Tomorrow's Schools: Accountability or control? Delta, 41, 3-11.

Cuttance, P. (1989). Performance indicators for schooling. A report to the Scottish Education Department.

Cuttance, P. (1994). Monitoring educational quality through performance indicators for school practice. School Effectiveness and School Improvement, 5(2), 101-126.

Education Review Office. (1994). Self-review in schools: The extent to which effective self-review is being implemented in schools. National Education Evaluation Report. No. 3 (Autumn). Wellington: Education Review Office.

Flynn, N. (1986). Performance measurement in public sector services. Policy and Politics,14(3), 389-404.

Frater, G. (n.d.). Using performance indicators to measure the quality of learning and teaching in schools. Unpublished internal report. Wellington: Education Review Office.

Gray, J. \& Wilcox, B. (1993). Performance indicators: Flourish or perish? In K. A. Riley and D. L. Nuttall (Eds.), Measuring quality: Education indicators - United Kingdom and international perspectives. (1994). London: Falmer Press.

Gray, J. \& Wilcox, B. (Eds.), (1995). "Good School, Bad School": Evaluating performance and encouraging improvement. London: Open University Press.

Helsby, G. \& Saunders, M. (1993). Taylorism, Tylerism and performance indicators: Defending the indefensible? Educational Studies, 19(1), $55-77$. 
Hopkins, D. (1991). International education indicators: Conceptual and theoretical aspects: Process indicators for school improvement. Report to the General Assembly of the INES Project International Education Indicators, Lugano-Cadro, Switzerland, September. Paris: Centre for Educational Research and Innovation.

Irving, J. (1993). Monitoring the education system. Delta, 47, 69-78.

Laugeson, M. (1993). Education Review Office: Internal auditor for the Executive (in the education sector). Public Sector, 1(3), 7-10.

Minister of Education. (1996). New Zealand schools: A report on the compulsory schools sector in New Zealand. Wellington: Learning Media.

Ministerial Working Party on Assessment for Better Learning. (1990). Tomorrow's Standards. Report of the Ministerial Working Party on Assessment for Better Learning. Wellington: Learning Media.

Ministry of Education. (1990). Quality education for all according to their needs: Brief for the incoming Government (October). Wellington: Ministry of Education.

Ministry of Education. (1994). Assessment: Policy to practice. Wellington: Learning Media.

Ministry of Education. (1995). Changing directions, roles and responsibilities in education. New Zealand Country Paper, OECD Conference on Better Schools, Paris, March 15-17.

Nuttall, D. (1994). Choosing Indicators. In K. A. Riley \& D. L. Nuttall (Eds.), Measuring quality: Education indicators - United Kingdom and international perspectives. London: Falmer Press.

Oakes, J. (1986). Educational indicators: A guide for policy-makers. New Jersey: Rutgers University, Centre for Policy Research in Education.

Organisation for Economic Cooperation and Development. (1996). Evaluating and Reforming Education Systems. Paris: OECD.

Riley, K. (1994). Following the education indicators trail in the pursuit of quality. In K. A. Riley \& D. L. Nuttall (Eds.), (1994). Measuring quality: Education indicators - United Kingdom and International Perspectives. London: Falmer Press.

Ruby, A. (1994). Schooling and value for money. Notes for an address to the OECD Conference on Quality in Schools, Auckland, August 1-3.

Ruby, A. \& Wyatt, T. (1988). Education indicators: Concepts, definitions and issues. Bulletin 5, Reporting on educational progress: Performance indicators in education. Sydney: Australian Conference of DirectorsGeneral of Education.
Scheerens, J. (1990). School effectiveness research and the development of process indicators of school functioning. School Effectiveness and School Improvement, 1(1), 61-80.

Spee, A. \& Bormans, R. (1992). Performance indicators in governmentinstitutional relations: The conceptual framework. Higher Education Management, 4(2), 139-155.

Taylor Fitz-Gibbon, C. (1996). Monitoring education. London: Cassell.

Watt, J. (1990). Performance indicators in education: What is their place? In T. Wyatt (Ed.), Indicators and quality in education: Papers from the Second National Conference 1989 (Volume 2), Australian Conference of Directors-General of Education, Sydney.

Wyatt, T. (Ed.). (1990). Indicators and quality in education: Papers from the Second National Conference 1989 (Volume 2), Australian Conference of Directors-General of Education, Sydney.

Wyatt, T., Ruby, A., Norton, S., Davies, B., \& Shrubb, S. (1989). Reporting on educational progress: Performance indicators in education. A report to the Conference of Directors-General of Education, Sydney (May).

Wylie, C. (1994). Self-managing schools in New Zealand: The fifth year. Wellington: New Zealand Council for Educational Research.

\section{The author}

Barbara Annesley has recently completed her Master of Education degree at Victoria University and is currently employed as a policy analyst in the Ministry of Education. 